\title{
Physical Activity Behavior Patterns during School Leisure Time in Children
}

\author{
Chad Smith \\ Department of Health Promotion and Human Performance, Weber State University, Ogden, Utah, USA. \\ 3848 Harrison Blvd, Ogden, UT. 84408, USA \\ E-mail: chadsmith6@weber.edu \\ James C. Hannon \\ College of Physical Activity and Sport Sciences, West Virginia University, Morgantown, West Virginia, USA. \\ 375 Birch St., Morgantown, WV. 26505, USA \\ E-mail: james.c.hannon@hsc.utah.edu \\ Timothy A. Brusseau \\ Department of Exercise and Sport Science, University of Utah, Salt Lake City, Utah, USA. \\ 250 S. 1850 E. Rm 200, Salt Lake City, UT. 84112, USA \\ E-mail: tim.brusseau@utah.edu \\ You Fu \\ Department of Kinesiology and Sports Sciences, University of Nebraska Kearney, Kearney, Nebraska, USA. \\ 905 W. 25th St. Kearney, NE. 68849, USA \\ E-mail: fuy2@unk.edu \\ Ryan D. Burns (Corresponding author) \\ Department of Exercise and Sport Science, University of Utah, Salt Lake City, Utah, USA. \\ 1036 University Village, Salt Lake City, Utah 84108, USA \\ E-mail: ryan.d.burns@utah.edu
}

Received: 15-10- 2015

Accepted: 13-12- 2015

Published: 08-01- 2016

doi:10.7575/aiac.ijkss.v.4n.1p.17

URL: http://dx.doi.org/10.7575/aiac.ijkss.v.4n.1p.17

\begin{abstract}
Optimizing physical activity (PA) in children is paramount to attenuate the incidence of chronic disease and to improve social and cognitive health. Limited research exists examining the observed PA patterns during school leisure times in children from the U.S. The purpose of this study was to examine the observed PA patterns of children during three school leisure times: before school, during lunch, and after school. The SOPLAY instrument was used to observe PA during the three leisure times across six weeks at four elementary schools in the U.S. Observer PA counts were stratified by sex, PA intensity (sedentary, walking, and very active), and leisure time. Multi-level models were employed to examine the effect of leisure time and PA intensity on observer PA counts, adjusting for day and schoollevel clustering. Lunch displayed the greatest number of counts for sedentary, walking, and very active PA intensities ( $p$ $<0.001)$. In boys, a greater number of observer counts in the very active PA intensity were recorded compared to the sedentary intensity before school $(\beta=10.34, p=0.04)$ and during lunch $(\beta=15.57, p<0.001)$. Girls did not display any differences among the PA intensities within before school and lunch leisure times $(p>0.05)$. After school displayed the fewest counts for walking and very active PA in both sexes $(p<0.05)$. An emphasis should be placed on increasing walking and very active PA intensities before school and during lunch in girls and after school in both sexes.
\end{abstract}

Keywords: after school, before school, lunch, SOPLAY, systematic observation

\section{Introduction}

The benefits of optimal levels of moderate-to-vigorous physical activity (MVPA) are numerous (Armstrong, Tomkinson, \& Ekelund, 2011; Blair et al., 1995; Boddy et al., 2014), yet less of one-half of children aged 6 to 11 years meet the recommended daily levels (Troiano et al., 2008). Children and adolescents aged 6 to 17 years are recommended to participate in at least 60 minutes or more of MVPA during the day (U.S. Department of Health and Human Services, 2008). Optimal MVPA has been linked to decreases in the incidence in chronic disease due to its direct effect on metabolic efficiency and cardiorespiratory function (Boddy et al., 2014), in addition to improving academic performance by moderating psychological arousal (Castelli, Hillman, Buck, \& Erwin, 2007; Taras, 2005; 
Trudeau, \& Shephard, 2010). Despite these benefits of MVPA, achieving optimal levels is a challenge in elementary school-aged children because the majority of time spent in academic classes is sedentary (Stewart, Dennison, Kohl, \& Doyle, 2004). However, there are opportunities for children to engage in structured or unstructured physical activity (PA) during specific school leisure times including before school, during lunch, and after school.

Numerous research studies have examined PA patterns in school-aged children during physical education and at recess (Fernandes, \& Sturm, 2011; Gao, Oh, \& Sheng, 2011; Hannon, 2008; Mota et al., 2005; Ridgers, Stratton, Fairclough, \& Twisk, 2007), however little research has examined PA behaviors during school leisure times. Leisure time represents a minor proportion of the school day, however it is an important time for children as it allows a break from their academic classes, provides time to socialize with peers, and provides opportunities to participate in active play (Mota et al., 2005; Stellino, Sinclair, Partridge, \& King, 2009). Participating in active play is particularly important because it is estimated that only $3.8 \%$ of elementary schools in the U.S. offer daily physical education (Lee, Burgeson, Fulton, \& Spain, 2007), thus there is limited opportunities to accumulate a significant amount of PA during the school day. This is also considering that children and adolescents tend to participate in more MVPA during school days compared to non-school days (Brusseau et al., 2011).

Recess has been shown to account from anywhere between $11 \%$ and $21 \%$ of total daily step counts and up to $40 \%$ of the daily MVPA recommendation in children (Ridgers, Stratton, \& Fairclough, 2006). Indeed, McKenzie, Crespo, Baquero, \& Elder (2010) found that during recess children had the greatest odds of participating in MVPA. However, the No Child Left Behind Act in the U.S. substantially decreased physical education and recess time by as much as 40 to 50 minutes per week in some school districts (Center on Educational Policy, 2008). Therefore, the before school, lunch, and after school leisure times are, in many schools, the only available times where a child can engage in active play on a daily basis. It is therefore crucial to maximize PA behaviors during these leisure times, not only to increase health benefits of MVPA, but also to moderate psychological arousal, which can optimize learning and memory retention during academic classes (Harrison, \& Narayan, 2003; Shepard, 1997).

Limited research has focused on the relationships between school day leisure time and PA behaviors in children. A summary of select pertinent studies examining school day physical activity behaviors in children are provided in Table 1. McKenzie et al. (2010) used systematic observation to show that children were more physically active at lunch and at recess compared to before school. The study provided valuable information regarding the need to increase MVPA behaviors before school in elementary school aged children, but after school PA behaviors were not assessed. After school may provide children additional opportunity to engage in active play (Trost, Rosenkranz, \& Dzewaltowski, 2008), and it is important that comparisons be made to the lunch and before school leisure times, not only to examine the total number of sedentary and MVPA behaviors, but also the relative distribution of PA intensity within each specific leisure time. Therefore, the purpose of this study was to explore the relationships between school day leisure time and PA intensity on daily PA observer counts in elementary school-aged children. It was hypothesized that children would display a greater number of MVPA behaviors during lunch compared to the before and after school leisure times.

\section{Method}

\subsection{Participants}

Participants were elementary school-aged children recruited from the $\mathrm{K}-6^{\text {th }}$ grades across four elementary schools located in the Mountain West Region of the United States. Students from each of the four schools were observed five times per week, Monday through Friday, for six continuous weeks at three specific leisure times: before school, during lunch, and after school. Students were observed for a total of 30 days per school throughout the Fall semester. The observers visited a total of 360 target areas and recorded a total number of 44627 PA counts, each count with an associated sex, PA intensity, and leisure time classifier.

\subsection{Instrumentation}

The System for Observing Play and Leisure Activity in Youth (SOPLAY) was used as the instrument to collect PA count data. SOPLAY uses systematic observation methodology via Placheck recording (i.e., Planned Activity Check) to scan target areas for PA behaviors (McKenzie, Marshall, Sallis, \& Conway, 2000). PA behaviors were coded as sedentary (lying down, sitting, or standing), walking, or very active (vigorous; running, jumping, skipping, climbing). The walking and very active intensity categories can be further summed to create a MVPA score. These activity codes have been previously validated using heart rate monitoring and accelerometers (Ridgers, Stratton, \& McKenzie, 2010; Rowe, Schuldheisz, \& van der Mars, 1997; Saint-Maurice, Welk, Ihmels, \& Krapfl, 2011). Prior to data collection, observers were trained on the SOPLAY instrument by the primary investigator using pre-coded behavioral vignettes on videotape. All trainers were required to meet set criteria to ensure observer reliability using the instrument (ICC $>0.90$ ). 
Table 1. Summary of various segmented school physical activity (PA) studies

\begin{tabular}{|c|c|c|c|}
\hline Study Authors & Study Year & $\begin{array}{l}\text { PA Measurement } \\
\text { Instrument }\end{array}$ & Primary Findings \\
\hline Turdor-Locke et al. & 2006 & Pedometer & $\begin{array}{l}\text { Lunchtime recess, } \\
\text { followed by PE and } \\
\text { afternoon recess were } \\
\text { the most important } \\
\text { school segments }\end{array}$ \\
\hline McKenzie et al. & 2010 & SOPLAY & $\begin{array}{l}\text { Children were more } \\
\text { physically active } \\
\text { during lunch and at } \\
\text { recess compared to } \\
\text { before school }\end{array}$ \\
\hline Brusseau et al. & 2011 & Pedometer & $\begin{array}{l}\text { Majority of steps } \\
\text { occurred outside of } \\
\text { school. Lunch recess } \\
\text { most steps for boys, } \\
\text { PE for girls }\end{array}$ \\
\hline Fairclough et al. & 2012 & Accelerometers & $\begin{array}{l}\text { High active youth } \\
\text { accumulated majority } \\
\text { of activity outside of } \\
\text { school, whereas low } \\
\text { active youth } \\
\text { accumulated most } \\
\text { activity during school }\end{array}$ \\
\hline Brusseau et al. & 2013 & Pedometer & $\begin{array}{l}\text { Outside of school } \\
\text { resulted in highest } \\
\text { steps but nearly } 25 \% \\
\text { total steps from PE } \\
\text { for American Indian } \\
\text { children }\end{array}$ \\
\hline Brusseau & 2015 & Pedometer & $\begin{array}{l}\text { Majority of PA } \\
\text { outside of school, } \\
\text { although poor } \\
\text { weather led to } \\
\text { increased percentage } \\
\text { at school, } 16 \% \text { from } \\
\text { PE, } 11.5 \% \text { from } \\
\text { recess }\end{array}$ \\
\hline Gao et al. & 2015 & Pedometer & $\begin{array}{l}34.2 \% \text { steps from } \\
\text { after school, } 14 \% \\
\text { recess }\end{array}$ \\
\hline Burns et al. & 2015 & Pedometer & $\begin{array}{l}\text { Lunch and afternoon } \\
\text { recess predicted } \\
\text { students meeting } \\
\text { daily } \\
\text { recommendations }\end{array}$ \\
\hline
\end{tabular}

\subsection{Procedures}

Observations were made in distinct target areas on school grounds during each leisure time. Target areas were potential play areas fully accessible to all students and were not sub-divided for further analysis. Target areas were clean areas (i.e., free of garbage, broken glass, etc.) located outdoors in close proximity to each school's main building. The target 
areas involved playgrounds (slides, swings, monkey bars, etc.), open grass fields, and concrete blacktop basketball courts. Target areas were chosen based on the prevalence of children in the play area on the days before the commencement of the study.

Inter-observer reliability was calculated before data collection at each school using videotaped physical activity sessions of children aged 6 to 12 years. Inter-observer intraclass correlations were ICC $>0.80$ within each sex-specific intensity level, thus inter-rater agreement was determined to be strong. One trained observer scanned the target area during each specific observation period. The observer scanned each target area for PA behaviors that were coded as sedentary (lying down, sitting, or standing), walking, or very active (running, jumping, climbing, skipping, etc.). Each scan was made left to right across the target area and separate scans were made for girls and boys. Final counts in PA behaviors during each leisure time at a specific target area included initial PA behaviors in the target area (one initial scan) plus 15 minutes worth of scanning. Each scan was for 5-seconds and each period of observation was 15 minutes in duration. Therefore, each observation period consisted of 180 separate scans.

Before school observations commenced approximately 15 minutes before school. The lunch observations commenced 15 minutes after the start of lunchtime and included three separate lunch periods. To calculate the lunch count for a respective school day, counts within each of the PA intensities were averaged across the three lunch periods. Finally, after school observations commenced 15 minutes after the final school bell. Each scan was sex specific and successive scanning was alternated between girls and boys. Each sex-specific child in the target area was counted only once per scan to account for redundant behavior. If the same child displayed a different behavior during a separate scan, the observer recorded the unique behavior for that respective child. The aforementioned procedures are in accordance to the recommended protocols described in the SOPLAY manual.

\subsection{Data Analysis}

PA count data within each of the PA intensities were screened for outliers using boxplots and checked for Gaussian distributions using histograms. The preliminary analysis included a 2 × 3 Factorial ANOVA test to examine the mean differences between sexes and among PA intensities (sedentary, walking, very active) on observer PA counts. If a statistically significant main effect was found for PA intensity, a Bonferroni post hoc test was employed with the alpha level adjusted using the Bonferroni method.

The primary analysis included using multi-level mixed effects models with random intercepts to examine the differences among leisure times (Level 1) on daily PA observer counts within each specific intensity, adjusting for the clustering by school day (Level 2; leisure times within each day) and school (Level 3; days within each school). The before school leisure time was the referent for all comparisons. This analysis yielded three separate models, one for each of the PA intensities.

A secondary analysis was employed using multi-level mixed effect models with random intercepts to examine the effect of PA intensity (Level 1) on PA observer counts within each specific leisure time, adjusting for day (Level 2) and school-level clustering (Level 3). Separate models were examined for girls and boys to control for a possible modifying effect. Sedentary behavior was the referent for all comparisons. This analysis yielded six separate models, one for each sex within each of the leisure times. For each of the aforementioned models, the day cluster represented each individual day of observation across the 30-day observation period at each school. The school level was each individual school observed in this study. Parameter estimates were calculated using unstructured covariance among the random effects and a maximum likelihood estimate. Alpha level was set at $p \leq 0.05$ and all analyses were performed using STATA v13.0 statistical software package (College Station, TX, USA).

\section{Results}

The descriptive data for average PA counts per school day within each of the PA intensities and leisure times for girls and boys are presented in Table 2 and Table 3, respectively. Preliminary analyses examining sex and leisure time differences on PA counts did not reveal any statistically significant main effects for $\operatorname{sex}(\mathrm{F}(1,418)=0.02, p=0.90)$ but did reveal a statistically significant main effect for leisure time $(\mathrm{F}(2,418)=316.44, p<0.001)$. Post hoc tests revealed that lunch had a greater average daily PA count than before school (Mean $\Delta=30.14, p<0.001$ ) and after school (Mean $\Delta=49.13, p<0.001)$, but there were no statistically significant differences in average daily PA counts comparing the before and after school leisure times $(p=0.239)$. Table 4 (See Appendix 1) shows the final fixed effects model solution for the leisure time slope parameter, stratified by PA intensity. Lunch displayed a greater number of PA counts in sedentary, walking, and very active PA compared to before school $(p<0.001)$. After school displayed fewer counts in sedentary and walking PA compared to before school $(p<0.001)$.

When examining the distribution of PA intensity counts within each of the leisure times, boys displayed a greater number of very active PA counts compared to sedentary counts before school $(\beta=10.34, p=0.04)$ and at lunch $(\beta=$ 15.57, $p<0.001)$. Girls did not display significant differences in PA intensity counts before school or during lunch $(p>$ 0.05). Therefore, only boys tended to display higher levels of MVPA compared to sedentary behaviors before school and at lunch. Both sexes displayed a fewer number of walking and very active PA counts compared to sedentary counts during the after school leisure time $(p<0.05$; see Table 2 and Table 3$)$. 
Table 2. Observed physical activity counts per school day within specific leisure times and intensities in girls (means and standard deviations)

\begin{tabular}{cccc}
\hline & Before School & Lunch & After School \\
\hline Sedentary Counts & $44.5 \pm 12.1$ & $76.7 \pm 10.8$ & $37.2 \pm 24.9$ \\
Walking Counts & $48.3 \pm 18.4$ & $73.6 \pm 14.7$ & $\mathbf{2 6 . 2} \pm \mathbf{1 8 . 9}$ \\
Very Active Counts & $45.8 \pm 27.1$ & $79.7 \pm 14.2$ & $\mathbf{6 . 1} \pm \mathbf{4 . 2}$ \\
\hline
\end{tabular}

Description: Bold denotes statistically significant differences compared to sedentary (referent) within each leisure time.

Table 3. Observed physical activity counts per school day within specific leisure times and intensities in boys (means and standard deviations).

\begin{tabular}{cccc}
\hline & Before School & Lunch & After School \\
\hline Sedentary Counts & $39.7 \pm 14.2$ & $69.8 \pm 10.9$ & $35.4 \pm 16.67$ \\
Walking Counts & $45.6 \pm 13.5$ & $70.3 \pm 8.7$ & $\mathbf{1 2 . 2} \pm \mathbf{1 2 . 5 7}$ \\
Very Active Counts & $\mathbf{5 0 . 2} \pm \mathbf{2 0 . 1}$ & $\mathbf{8 4 . 4} \pm \mathbf{8 . 9}$ & $\mathbf{9 . 1} \pm \mathbf{5 . 6}$ \\
\hline
\end{tabular}

Description: Bold denotes statistically significant differences compared to sedentary (referent) within each leisure time.

\section{Discussion}

The purpose of this study was to examine the differences among school day leisure times and PA intensity levels on daily observer PA counts in elementary school-aged children. The results show that the lunch leisure time displayed the greatest number of sedentary, walking, and very active behaviors compared to the other leisure times. Additionally, boys tended to display a greater number of very active PA counts compared to sedentary counts before school and during lunch, while girls did not display significant differences in PA intensity counts before school or during lunch. The after school leisure time yielded significantly fewer walking and very active observer counts compared to sedentary in both sexes. This study expands on the research conducted by McKenzie et al. (2010), including after school as a segmented leisure time and adjusting for the clustering effects of school day and school on the parameter estimates. The results support previous studies suggesting that the most active leisure time, outside of recess, during the day for children is during lunch (McKenzie et al., 2000; McKenzie et al., 2010), and that girls tend to display fewer MVPA patterns compared to boys (Howe et al., 2011). Lack of MVPA behaviors during school leisure time limits the odds of a child meeting recommended daily PA levels. Reasons why children displayed limited MVPA behaviors during the after school leisure time are multi-faceted and should be explored with additional research.

Of the three leisure times examined in this study, after school tended to display the fewest counts of walking and very active PA behaviors compared to before school and lunch. After school is a transition time for most children to break from their academic classes and wait for their transportation (e.g., buses, car pools, etc.) to their homes or after school programs. Despite an opportunity for these children to engage in active play during this transition period (Beets, Huberly, \& Beighle, 2012), few children actively participated in the target areas. Many children may have already been transported off campus or were waiting within school buildings for their transportation; therefore engaging in the observed target areas was either restricted or not desirable because other children were not in the play area. A possible strategy to increase PA during the after school leisure time is to have faculty or staff organize structured or semistructured play while children are waiting for their transportation. This will inherently increase their daily activity levels and make the after school leisure time more enjoyable for some children, especially those who have extended wait times.

Approximately $56 \%$ of all public elementary schools have reported on-site after school programs (Parsad, \& Lewis, 2009). The number of children in after school programs may continue to rise given that there is a growing number of households in which both parents work. This phenomenon coupled with the decreases in PA opportunities during the school day for children increases the need for effective health-based after school programs. Several interventions have shown effectiveness on increasing MVPA in after school settings, however limitations to these interventions is staff turnover and training, as it has been demonstrated that the efficacy of PA and nutritional intervention programs is correlated with the quality of staff training. Therefore, it is important that schools recognize staff as more than just "babysitters" when attempting to implement PA interventions during specific leisure times and provide proper training to ensure optimal implementation of school PA programs.

Before school also displayed compromised MVPA behaviors compared to lunch. Before school is another transition leisure period for elementary school-aged children. Many of the behaviors displayed during this time period were sedentary as children were waiting for the first class period to commence. The results from this study support previous research showing a lack of MVPA behaviors before school (McKenzie et al., 2000; McKenzie et al., 2010). PA before school is important as it will not only increase daily PA levels and energize students for the day ahead, but also research has shown that MVPA has an acute psychological effect by moderating arousal that can optimize focus and memory retention needed for learning in the classroom (Budde, Voelcker-Rehage, Pietrabyk-Kendziorra, Ribeiro, \& Tidow, 
2008; McNaughten, \& Gabbard, 1993; Molloy, 1989)). Additionally, many students who display significant levels of off-task behavior in the classroom due to hyperactivity may find improvement in increasing their on-task behaviors with optimal levels of MVPA before school hours (Mahar et al., 2006).

Previous research has identified effective strategies to increase PA before school. One effective strategy is to include "energizer" or "drop-in" activities, where teachers use structured play for 10 to 15 minutes before the first class period of the day. These activities can incorporate academic content but the goal is to increase MVPA behavior using enjoyable group oriented play activities for children. Allowing access to playground and play areas is also an effective strategy to increase PA before school. These areas may be restricted before the school day because of a lack of supervision. If schools can allow access to these play areas by including a faculty or staff supervisor on site, children will have more opportunity to participate in active play.

Even though lunch displayed the greatest number of walking and very active behaviors during any other school leisure time, there were still a significant number of displayed sedentary behaviors. School lunch normally incorporates mealtime and playtime in many elementary schools. Students have the opportunity to engage in unstructured active play following their lunchtime meal, however many students do not take advantage of this opportunity and remain in sedentary behavior for the duration of the leisure time. A strategy to possibly attenuate the excess sedentary behaviors seen during lunch is to provide options for children to engage in either structured or unstructured play. As stated previously, structured play is shown to increase MVPA compared to unstructured play during recess in elementary school-aged children (Howe, Freedson, Alhassan, Feldman, \& Osganian, 2011; Scruggs, Beveridge, \& Watson, 2003). Structured activities, led by a school faculty or staff member, may increase PA participation and enjoyment in children. Another strategy to increase PA behaviors would be providing additional play equipment during lunchtime. Previous studies have shown that various types of play equipment such as balls, jump ropes, hula-hoops, etc. significantly increase MVPA behaviors in children during school leisure times (Farley, Meriweather, Baker, Rice, \& Webber, 2007; Gubbles, Van Kann, \& Jansen, 2012). Providing additional equipment during lunch is an effective strategy to provide children options for engaging in healthy PA behaviors to increase their overall daily PA levels.

Numerous research studies have shown that boys are more physically active than girls and that girls tend to spend more time in sedentary behaviors than boys during school leisure time (Beighle et al., 2006; Sarkin, McKenzie, \& Sallis, 1997). This trend was supported in this study by showing that boys tended to display a greater number of very active PA counts relative to sedentary counts before school and at lunchtime, while girls did not display any differences between very active and sedentary behaviors before school or during lunch. A strategy to possibly increase MVPA in girls is by providing sex-specific structured activities, led by a school faculty or staff member, which may increase PA participation and enjoyment during leisure time. Another strategy may be to provide gender-specific equipment during leisure time. Previous studies have shown that various types of play equipment such as balls, jump ropes, hula-hoops, etc. significantly increase MVPA behaviors in children (Farley et al., 2007; Gubbles, Van Kann, \& Jansen, 2012). Providing gender-specific equipment during leisure time is an effective strategy to provide girls and boys appealing options for engaging in healthy active play.

Limitations to this study must be considered before any generalizations can be made. Schools observed in this study were from the Mountain West region of the US and data were collected across 30 days during the Fall semester, therefore the external validity of the results is questionable when compared other geographical regions, during Spring semester, or using longer periods of observation. Additionally, PA data were collected using a systematic observation instrument (SOPLAY); therefore the information pertaining to intensity of PA may not be as valid compared to more objective methods of measurement such as accelerometers. Although objective methods of PA such as pedometers and accelerometers are valid indicators of behaviors, they are often cumbersome to administer to large population samples. Systematic observation has the benefit of observing large number of groups of individuals (e.g. student bodies) in distinct settings and time periods (e.g. at a specific play area before school). Validated systematic observation instruments, such as SOPLAY, have been used extensity in PA surveillance research and the codes for PA intensity have been validated using heart rate monitoring and accelerometers in children and adolescents. Finally, PA systematic observation scanning occurred for exactly 15 minutes before school, during lunch, and after school. Therefore, total PA behaviors during these leisure times, including behaviors prior to and following observer scanning, may have been misrepresented. However, 15 minutes of scanning for systematic observation represented a significant proportion of each specific leisure time, therefore it is believed that the representations of PA behaviors were valid.

\section{Conclusion}

In conclusion, lunch displayed the greatest number of sedentary, walking, and very active PA counts compared to the other school leisure times. Boys tended to display a greater number of very active PA counts compared to sedentary PA counts before school and at lunch. Girls did not display significant differences in PA intensity counts before school or during lunch. MVPA behaviors were compromised after school in both sexes. An emphasis should be placed on increasing MVPA behaviors before school and during lunch in girls and after school in both sexes. Other important school segments such as PE should strive to increase PA behaviors to compensate for lower PA before and after school hours. 


\section{Acknowledgements}

The authors would like to thank the schools and students who participated in this study. The authors would also like to thank the graduate students who assisted in the data collection process.

\section{References}

Armstrong, N., Tomkinson, G., \& Ekelund, U. (2011). Aerobic fitness and its relationship to sport, exercise training and habitual physical activity during youth. British Journal of Sports Medicine, 45, 849-58. http://dx.doi.org/10.1136/bjsports-2011-090200

Beets, M. W., Huberly, J., \& Beighle, A. (2012). Physical activity of children attending after school programs. American Journal of Preventive Medicine, 42, 180-184. http://dx.doi.org/10.1016/j.amepre.2011.10.007

Beighle, A., Morgan, C. F., LeMasurier, G., \& Pangrazi, R. P. (2006). Children's physical activity during recess and outside of school. Journal of School Health, 76, 516-520. http://dx.doi.org/10.1111/j.1746-1561.2006.00151.x

Blair, S. N., Kohl, H. W., Barlow, C. E., Paffenbarger, R. S., Gibbons, L. W., \& Macera, C. A. (1995). Changes in physical fitness and all-cause mortality: a prospective study of healthy and unhealthy men. Journal of the American Medical Association, 273, 1093-1098. http://dx.doi.org/10.1001/jama.1995.03520380029031

Boddy, L. M., Murphy, M. H., Cunningham, C., Breslin, G., Gobbi, R., Graves, L. E., ... Stratton, G. (2014). Physical activity, cardiorespiratory fitness, and clustered cardio-metabolic risk in 10- to 12-year-old school children: The REACH Y6 study. American Journal of Human Biology, 26, 446-451. http://dx.doi.org/10.1002/ajhb.22537

Brusseau, T. A., Kulinna, P. H., Tudor-Locke, C., Ferry, M., Van Der Mars, H., \& Darst, P. W. (2011). Pedometer determined segmented physical activity patterns of fourth and fifth grade children. Journal of Physical Activity and Health, 8, 279-286.

Brusseau, T. A., Kulinna, P. H., Tudor-Locke, C., \& Ferry, M. (2013). Daily physical activity patterns of children living in an American Indian community. Journal of Physical Activity and Health, 10, 48-53.

Brusseau, T. A. (2015). The Intricacies of Children's Physical Activity. Journal of Human Kinetics, 47, $269-275$.

Budde, H., Voelcker-Rehage, C., Pietraßyk-Kendziorra, S., Ribeiro, P., \& Tidow, G. (2008). Acute coordinative e xercise improves attentional performance in adolescents. Neuroscience Letters, 441, 219-223. http://dx.doi.org/10.1016/j.neulet.2008.06.024

Burns, R. D., Brusseau, T. A, \& Hannon, J. C. (2015). Prediction of optimal daily step count achievement from segmented school physical activity. Advances in Public Health. http://dx.doi.org/10.1155/2015/496248

Castelli, D. M., Hillman, C. H., Buck, S. M, \& Erwin, H. E. (2007). Physical fitness and academic achievement in third and fifth grade students. Journal of Sport and Exercise Psychology, 29, 239-252.

Center on Educational Policy (2008). Instructional Time in Elementary Schools: A Closer Look at Changes for Specific Subjects. Washington, DC: Center on Educational Policy.

Fairclough, S. J., Beighle, A., Erwin, H., \& Ridgers, N. D. (2012). School day segmented physical activity patterns of high and low active children. BMC Public Health, 12, 406. http://dx.doi.org/10.1186/1471-2458-12-406

Farley, T. A., Meriwether, R. A., Baker, E. T., Rice, J. C., \& Webber, L. S. (2008). Where do children play? The influence of playground equipment on physical activity of children in free play. Journal of Physical Activity and Health, $5,319-331$.

Fernandes, M., \& Sturm, R. (2011). The role of school physical activity programs in child body mass trajectory. Journal of Physical Activity and Health, 8, 174-181.

Gao, Z., Oh, H., \& Sheng, H. (2011). Middle school students' body mass index and physical activity levels in physical education. Research Quarterly for Exercise and Sport, 82, 145-150. http://dx.doi.org/10.1080/02701367.2011.10599732

Gao, Y., Wang, J. J., Lau, P. W., \& Ransdell, L. (2015). Pedometer-determined physical activity patterns in a segmented school day among Hong Kong primary school children. Journal of Exercise Science \& Fitness, 13, $42-48$. http://dx.doi.org/10.1016/j.jesf.2015.03.002

Gubbles, J. S., Van Kann, D. H. H., \& Jansen, M. W. J. (2012). Play equipment physical activity opportunities, and children's activity levels at childcare. Journal of Environmental and Public Health. http://dx.doi.org/10.1155/2012/326520

Hannon, J. C. (2008). Physical activity levels of overweight and non-overweight high school students during physical education classes. Journal of School Health, 78, 420-431. http://dx.doi.org/10.1111/j.1746-1561.2008.00325.x 
Harrison, P. A., \& Narayan, G. (2003). Differences in behavior, psychological factors, and environmental factors associated with participation in school sports and other activities in adolescence. Journal of School Health, 73, 113120. http://dx.doi.org/10.1111/j.1746-1561.2003.tb03585.x

Howe, C. A., Freedson, P. S., Alhassan, S., Feldman, H. A., \& Osganian, S. K. (2011). A recess intervention to promote moderate-to-vigorous physical activity. Pediatric Obesity, 7, 82-88. http://dx.doi.org/10.1111/j.20476310.2011.00007.x

Lee, S. M., Burgeson, C. R., Fulton, J. E., \& Spain, C. G. (2007). Physical education and physical activity: results from the School Health Policies and Programs Study. Journal of School Health, 77, 435-463. http://dx.doi.org/10.1111/j.1746-1561.2007.00229.x

Mahar, M. T., Murphy, S. K., Rowe, D. A., Golden, J., Shields, A. T, \& Raedeke, T. D. (2006). Effects of a classroombased program on physical activity and on-task behavior. Medicine and Science in Sports and Exercise, 38, $2086-2094$. http://dx.doi.org/10.1249/01.mss.0000235359.16685.a3

McKenzie, T. L., Crespo, N. C., Baquero, B., \& Elder, J. P. (2010). Leisure-time physical activity in elementary schools: analysis of contextual conditions. Journal of School Health, 80, 470-477.http://dx.doi.org/10.1111/j.17461561.2010.00530.x।

McKenzie, T. L., Marshall, S. J., Sallis, J. F., \& Conway, T. L. (2000). Leisure-time physical activity in school environments: an observational study using SOPLAY. Preventive Medicine, 30, 70-77. http://dx.doi.org/10.1006/pmed.1999.0591

McNaughten, D., \& Gabbard, C. (1993). Physical exertion and immediate mental performance of sixth-grade children. Perceptual and Motor Skills, 77, 1155-1159. http://dx.doi.org/10.2466/pms.1993.77.3f.1155

Molloy, G. N. (1989). Chemicals, exercise and hyperactivity: A short report. International Journal of Disability, Development, and Education, 36, 57-61. http://dx.doi.org/10.1080/0156655890360106

Mota, J., Silva, P., Santos, M. P., Ribeiro, J. C., Oliveira, J., \& Duarte, J. A. (2005). Physical activity and school recess time: Differences between the sexes and the relationship between children's playground physical activity and habitual physical activity. Journal of Sports Sciences, 23, 269-275.http://dx.doi.org/10.1080/02640410410001730124

Mota, J., Suva, P., Santos, M. P., Ribeiro, J. C., Oliverira, J., \& Duarte, J. A. (2005). Physical activity and school recess time: differences between the sexes and the relationship between children's playground physical activity and habitual physical activity. Journal of Sports Sciences, 23, 269-275. http://dx.doi.org/10.1080/02640410410001730124

Parsad, B., \& Lewis, L. (2009). After-School Programs in Public Elementary Schools. (NCES 2009-043). National Center for Education Statistics, Institute of Education Sciences, U.S. Department of Education. Washington, DC.

Ridgers, N. D., Stratton, G., \& McKenzie, T. L. (2010). Reliability and validity of the System for Observing Children's Activity and Relationships during Play (SOCARP). Journal of Physical Activity and Health, 5, 17-25.

Ridgers, N. D., Stratton, G., Fairclough, S. J., \& Twisk, J. W. (2007). Long-term effects of a playground markings and physical structures on children's recess physical activity levels. Preventive Medicine, 44, 393-397. http://dx.doi.org/10.1016/j.ypmed.2007.01.009

Ridgers, N. D, Stratton, G., \& Fairclough, S. J. (2006). Physical activity levels of children during school playtime. Sports Medicine, 36, 359-371.http://dx.doi.org/10.2165/00007256-200636040-00005

Rowe, P. J., Schuldheisz, J. M., \& van der Mars, H. (1997). Measuring physical activity in physical education: validation of the SOFIT direct observation instrument for use with first to eighth grade students. Pediatric Exercise Science, 9, 136-49.

Saint-Maurice, P. F., Welk, G., Ihmels, M. A., \& Krapfl, J. R. (2011). Validation of the SOPLAY tool with an accelerometry-based physical activity monitor. Journal of Physical Activity and Health, 8, 1108-1116.

Sarkin, J. A., McKenzie, T. L., \& Sallis, J. F. (1997). Gender differences in $\square$ physical activity during fifth-grade physical education and $\square$ recess periods. Journal of Teaching Physical Education, 17, 99-106.

Scruggs, P. W., Beveridge, S. K., \& Watson, D. L. (2003). Increasing children's school time physical activity using structured fitness breaks. Pediatric Exercise Science, 15, 156-169.

Shephard, R. J. (1997). Curricular physical activity and academic performance. Pediatric Exercise Science, 9, $113-126$. Stellino, M. B., Sinclair, C. D., Partridge, J. A., \& King, K. M. (2009). Differences in children's recess physical activity: recess activity of the week intervention. Journal of School Health, 80, 436-444. http://dx.doi.org/10.1111/j.1746-1561.2010.00525.x

Stewart, J. A., Dennison, D. A., Kohl, H. W., \& Doyle, A. J. (2004). Exercise level and energy expenditure in the TAKE 10! in-class physical activity program. Journal of School Health, 74, 397-400. http://dx.doi.org/10.1111/j.17461561.2004.tb06605.x

Taras, H. (2005). Physical activity and student performance at school. Journal of School Health, 75, $214-218$. http://dx.doi.org/10.1111/j.1746-1561.2005.00026.x 
Troiano, R. P., Berrigan, D., Dodd, K. W., Masse, L. C., Tilert, T., \& McDowell, M. (2008). Physical activity in the United States measured by accelerometer. Medicine and Science in Sports and Exercise, 40, 181-188. http://dx.doi.org/10.1249/mss.0b013e31815a51b3

Trost, S. G., Rosenkranz, R. R., \& Dzewaltowski, D. (2008). Physical activity levels among children attending afterschool programs. Medicine and Science in Sport and Exercise, 40, 622-629. http://dx.doi.org/10.1249/MSS.0b013e318161eaa5

Trudeau, F., \& Shephard, R. J. (2010). Relationships of physical activity to brain health and the academic performance of school children. American Journal of Lifestyle Medicine, 4, 138-150. http://dx.doi.org/10.1177/1559827609351133

Tudor-Locke, C., Lee, S. M., Morgan, C. F., Beighle, A., \& Pangrazi, R. P. (2006). Children's pedometer-determined physical activity during the segmented school day. Medicine and Science in Sports and Exercise, 38, $1732-1738$. http://dx.doi.org/10.1249/01.mss.0000230212.55119.98

U.S. Department of Health and Human Services (2008). 2008 Physical Activity Guidelines for Americans. Washington, DC: US Department of Health and Human Services.

\section{Appendix 1}

Table 4. Leisure time parameter estimates for the final fixed-effect model solution per physical activity intensity (Referent $=$ before school; Dependent variable $=$ Physical activity counts per school day).

\begin{tabular}{|c|c|c|c|}
\hline & $\begin{array}{c}\beta \text { Coefficient } \\
(95 \% \text { C.I. })\end{array}$ & Standard Error & $p$-value \\
\hline \multicolumn{4}{|l|}{ Sedentary } \\
\hline Lunch & $\begin{array}{c}31.7 \\
(23.1,40.4)\end{array}$ & 4.4 & $<0.001$ \\
\hline After School & $\begin{array}{c}-35.7 \\
(-53.9,-17.5)\end{array}$ & 9.3 & $<0.001$ \\
\hline \multicolumn{4}{|l|}{ Walking } \\
\hline Lunch & $\begin{array}{c}24.8 \\
(11.3,38.3)\end{array}$ & 6.8 & $<0.001$ \\
\hline After School & $\begin{array}{c}-43.6 \\
(-64.5,-22.8)\end{array}$ & 10.6 & $<0.001$ \\
\hline \multicolumn{4}{|l|}{ Very Active } \\
\hline Lunch & $\begin{array}{c}35.5 \\
(16.8,54.2)\end{array}$ & 9.5 & $<0.001$ \\
\hline After School & $\begin{array}{c}-22.1 \\
(-45.4,1.1)\end{array}$ & 11.8 & 0.062 \\
\hline
\end{tabular}

